Information Technology; and Linda Magno, director of the Medicare Demonstrations Program Guide.

Hurricane Katrina wrecked the medical infrastructure along the Gulf Coast, according to Hill. Some 6,000 physician practices were affected, 4,500 of which were in 3 Louisiana parishes, he said. The average practice loss was $\$ 363,000$ after insurance coverage.

DeSalvo called for a health care system that mirrors the model of care espoused in the Future of Family Medicine report. New Orleans' pre-Katrina health system was the antithesis of that model, she said, adding that the FFM model will best serve patients, conserve resources and improve outcomes.

"Patients in the system experienced fragmented care delivered in clinics located inconveniently downtown and open during hours convenient to the physicians and trainees," she said of that pre-Katrina health care. "Other care in the city was generally providercentric, not supported by interoperable information technology or by health policies that financially supported primary care."

Worse, the system perpetuated itself by training physicians who expected to work in a subspecialtyfocused, hospital-based, provider-centered practice. "In reengineering the health system of New Orleans, planners propose to shift the paradigm away from this ... model," DeSalvo said. "Our ultimate vision for the postKatrina health system is one in which every citizen has a 'medical home' that provides high-value care that is responsive to their needs and perspectives."

Planners want a network of primary care practices that would be housed in community centers and that also would offer exercise facilities, child care and Internet access for patients, said DeSalvo. These health care clinics would offer group visits for chronic conditions, open-access scheduling, multidisciplinary teams and electronic health records. The clinics also would train residents and medical students "so that they are exposed to a patient-centric model of primary care," she said.

One clinic - the Covenant House-already is implementing the tenets of the planners' vision. The facility provides socioeconomic, recreational and health care services for residents from the surrounding neighborhood. Plans call for a multidisciplinary team that includes a social worker and counselor and a training program to expose students and residents to patientcentric care, said DeSalvo.

Leslie Champlin AAFP News Department

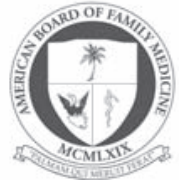

From the American

Board of Family Medicine

Ann Fam Med 2006;4:180-182. DOI: 10.1370/afm.531.

\section{MAINTENANCE OF CERTIFICATION FOR FAMILY PHYSICIANS}

In addition to its regular 7-year recertification process, in 2004 the American Board of Family Medicine (ABFM) began the implementation of its Maintenance of Certification for Family Physicians (MC-FP). The roll out of MC-FP was designed to gradually transition all Diplomates into this new program by 2010 by entering all physicians who certify or recertify into this new program in the year after they successfully pass the examination. The first group that entered MC-FP in 2004 was comprised of those physicians who certified or recertified in 2003; the last group to come in to the program in 2010 will be those who certify or recertify in 2009 .

The ABFM has recently modified the program to include more options and greater flexibility for Diplomates. The most important new enhancement is the opportunity for Diplomates to extend their certification period from 7 to 10 years by regularly completing $\mathrm{MC}$ FP requirements in a timely fashion.

\section{About the Program}

MC-FP is a mechanism that provides the ABFM with the means of continuously assessing Diplomates. Every specialty board that belongs to the American Board of Medical Specialties (ABMS) has agreed to a generic structure with which each of its individual programs must comply. This structure consists of 4 elements designed to assess 4 important physician characteristics: professionalism (Part I), self-assessment and lifelong learning (Part II), cognitive expertise (Part III), and performance in practice (Part IV). While these elements are similar to and consistent with the ABFM's long-standing, existing recertification program, MC-FP stresses the importance of ongoing participation in activities which evaluate each of these between recertification examinations - a requirement that ABFM believes encourages clinical excellence and benefits both physicians and their patients.

\section{Extending a Certificate from 7 to 10 Years}

As mentioned, one of the important new enhancements is the option to extend a recently earned 7 -year certificate by 3 years, effectively creating a 10 -year certification period. Under the original MC-FP program that 
began in 2004, each ABFM-certified Diplomate was required to maintain a current and valid license and complete 6 Self-Assessment Modules (SAMs) and 1 Performance in Practice Module (PPM) [or a METRIC module created by the American Academy of Family Physicians (AAFP)] before sitting for the recertification examination in the sixth or seventh year. A new option will allow Diplomates to complete 2 Part II modules (currently the SAMs) and 1 Part IV module (currently a PPM or METRIC) at their own pace in 3 separate 3-year windows (we call these stages).

Completing these requirements in a timely manner within the first two 3 -year stages will allow physicians to extend the life of their certificate from 7 to 10 years. Those Diplomates who are not able to complete these requirements will fall back to the original 7 -year cycle. It is important to note that the first 2 groups to enter MCFP in 2004 and 2005 (those who certified or recertified in 2003 and 2004, respectively) will be allowed to complete either 3 Part II modules or 2 Part II modules and 1 Part IV module to meet the requirements for the first 3-year stage only.

This major improvement in MC-FP will help Diplomates keep up with rapid advances in medicine, while duly recognizing the achievement of full and timely participation in MC-FP. Please see the schematic to visualize how this process will operate.

\section{Additional Program \\ Enhancements}

New options have been created for Part IV. In addition to the currently available PPMs and the AAFP's METRIC modules (one of which may be used to satisfy a Part IV requirement), 2 new types of modules have been created. Methods in Medicine Modules (MIMMs) will introduce Diplomates to important concepts that will help them in their day-to-day practice of medicine. The first MIMM, which will focus on information management, will be available in
2007 with more to follow. A Patient Safety Module (PSM), currently being produced by ABMS for use by all specialty boards, will come online no later than 2008. These new modules will create a rich menu from which Diplomates can select options to meet their Part IV requirements. The MIMMs and the PSM have been designed specifically to help Diplomates who do not practice or see patients in continuity meet their requirements. (Please note: those Diplomates in these categories who entered MC-FP in 2004 or 2005 can complete a SAM to meet their Part IV requirement for Stage One if they wish to choose the new 10-year cycle.).

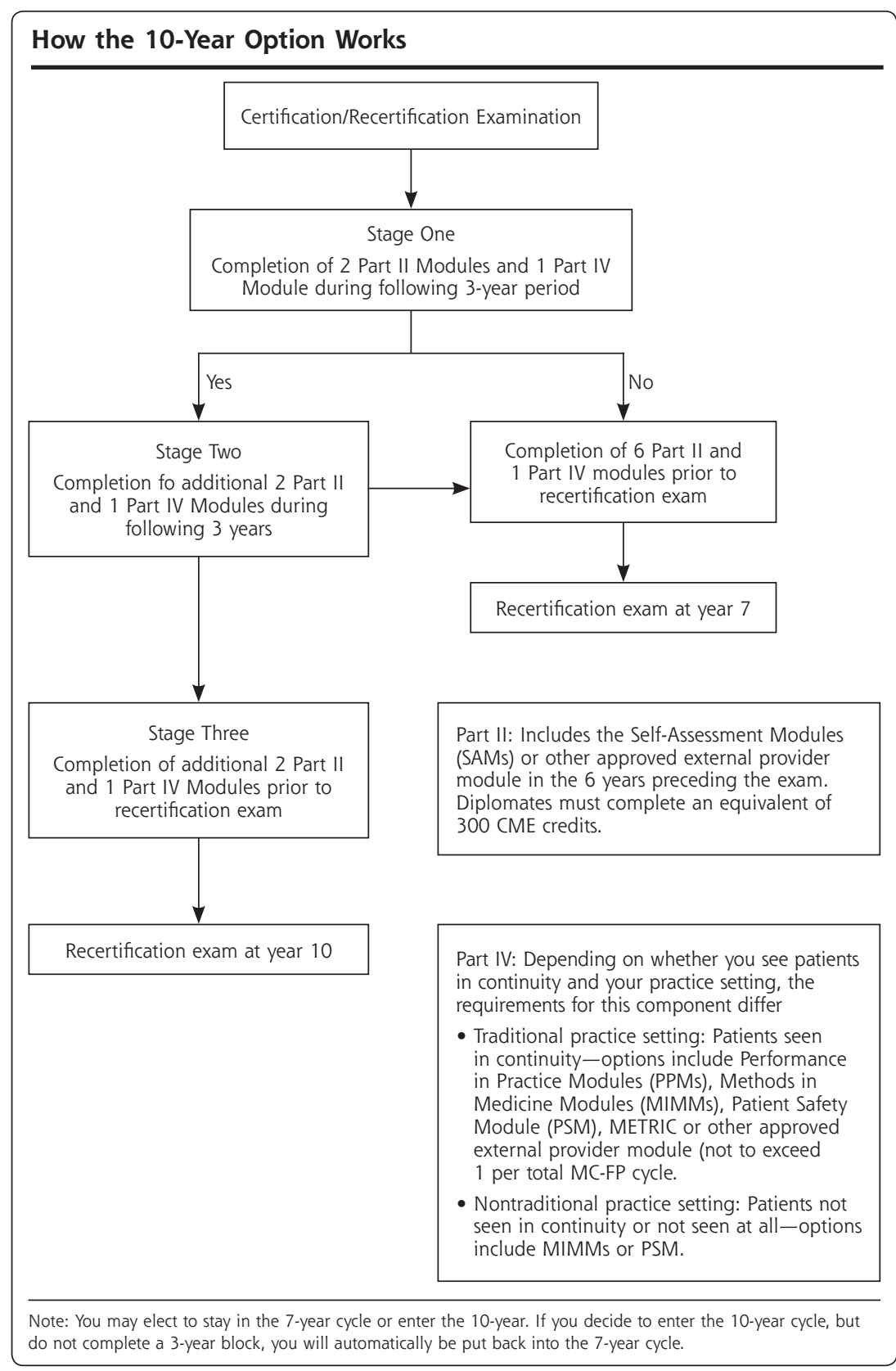




\section{Payment Options}

We will continue to offer similar payment options under the new plan. The new payment plan, to be implemented in January 2007, will result in a lower annualized cost over the 10-year MC-FP cycle for those Diplomates choosing either the full prepayment option or the annual payment option. Both of these payment options guarantee the total cost of MC-FP, including the examination.

For more details on existing and future payment options, as well as information for those Diplomates who certified or recertified in 2003, 2004 or 2005, please visit our Web site.

\section{Program Participation}

All Diplomates are eligible to choose the 10-year cycle, including those who are currently eligible for MC-FP but who have not started the process yet. For those Diplomates who were certified or recertified in 2003 or 2004, a limited amount of time exists to complete the requirement for Stage One. These Diplomates are encouraged to enroll in MC-FP and begin completion of their requirements immediately. The MC-FP Handbook, which can be accessed on our Web site, provides information on how to begin the process, payment options, and requirements for each of the 4 parts of MC-FP. Diplomates can track their progress in MC-FP through a unique online portfolio, which contains personal and professional history and assists Diplomates in monitoring their completion of the program requirements.

For more information visit our Web site at http:// www.theabfm.org or contact us directly for one-on-one assistance by calling our Help Desk at 1-877-223-7437.

Robert Cattoi

American Board of Family Medicine

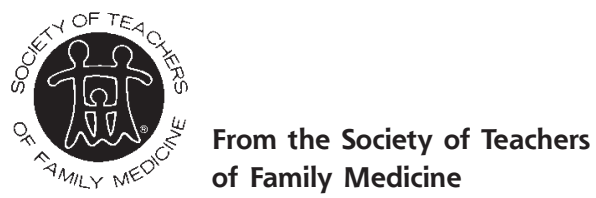

Ann Fam Med 2006;4:182-184. DOI: 10.1370/afm.533.

\section{ALIGNING THE INTERESTS OF OSTEOPATHIC AND ALLOPATHIC TEACHERS OF FAMILY MEDICINE}

"Integrating osteopathic training into family practice residencies has the potential of adding depth to any family practice residency program." "To survive as a unique medical entity, the osteopathic profession must curtail the ongoing exodus of young graduates from the philosophical roots of the profession, and both academic components and clinical components must be re-infused with the efficacious values inherent in the osteopathic approach to patient care." ${ }^{2}$

The themes represented in the above quotes are indicative of a wide breadth of views held by osteopathic and allopathic family medicine educators. But where is the common ground, and what do allopathic family medicine and particularly the Society of Teachers in Family Medicine (STFM) have to offer in helping to create a common ground?

From its inception, the osteopathic profession has been smaller in numbers than its allopathic counterpart and has worked hard to secure its place in American medicine. Over the past 100 years or so these efforts have produced a profession that is highly competent and growing, with 23 colleges of osteopathic medicine at present and more in development. This growth phase has coincided with other sweeping changes in the financing of American medicine that have led to mergers and acquisitions of hospitals that have all but eliminated many hospitals that were previously osteopathic. This has reduced the options for graduates of osteopathic medical schools to acquire internships and residencies in osteopathic hospitals.

Allopathic graduate medical education has also been challenged in recent years. After 9/11 it also became increasingly difficult to recruit qualified international graduates in the allopathic GME match process. This collision of coincidences has created a situation where graduates of osteopathic medical schools must find graduate medical education in allopathic programs at the same time that allopathic programs, especially in family medicine, are searching for qualified applicants. The resulting influx of osteopathic students into allopathic GME programs has been closely followed by the recruitment of new osteopathic faculty into allopathic residency programs. As a result of the expansion of both osteopathic and allopathic medical schools, there is also an increasing requirement for more qualified faculty. This would seem to imply a greater need for cooperation and collaboration between the 2 professions, especially in family medicine. So why does this not occur? Are the barriers to an improved working relationship that create such inertia cultural or political, related to economics or tradition, or simply a lack of knowledge about each profession and what it has to offer? Are there issues keeping the osteopathic profession from utilizing the expertise of organizations such as STFM?

These issues are part of a discussion that began at the STFM 2004 Annual Spring Conference in Toronto, where the STFM Membership Committee began to earnestly examine osteopathic membership. The issues relating to STFM membership may also reflect on the 